\title{
College Squirrels Gone Wild? Using Sciurus Carolinensis Behavior To Assess The Ecosystem Value Of Urban Green Spaces
}

Adam Kay ( $\square$ adkay@stthomas.edu )

UST: University of St Thomas https://orcid.org/0000-0001-6667-7645

Michael T. Hughes

University of St Thomas

Maddie G. Ammend

University of St Andrews Scottish Oceans Institute

Mckenzie R. Granger

University of St Thomas

Jake J. Hodge

University of St Thomas

Jamaal Mohamud

University of St Thomas

Ellie A. Romfoe

University of St Thomas

Halima Said

St Catherine University

Liam Selden

University of St Thomas

Alex L. Welter

University of St Thomas

Justa L. Heinen-Kay

University of St Thomas

\section{Research Article}

Keywords: Foraging-risk tradeoff, Landscape of fear, Road effect, Urban ecology

Posted Date: February 24th, 2022

DOI: https://doi.org/10.21203/rs.3.rs-1386470/v1 
License: (c) (i) This work is licensed under a Creative Commons Attribution 4.0 International License. Read Full License 


\section{Abstract}

Predicted rapid increases in urbanization in the face of accelerating biodiversity loss underscores the need for urban development that promotes rather than displaces native plants and animals. One approach for increasing urban biodiversity is through the development of "green infrastructure". Although research has explored urban-rural gradients and the overall value of urban green infrastructure, few studies have investigated the habitat value for wildlife of different types of urban greenspace. Here, we use a well-established metric in ecology, giving up-densities (GUDs), to compare foraging costs for a common urban wildlife species, the eastern gray squirrel (Sciurus carolinensis), among three green infrastructure categories: municipal parks, college campuses, and residential yards. We found that GUDs for gray squirrels did not differ significantly among location categories after controlling for proximity to roads, but proximity to roads was associated with significantly higher GUDs in all locations. In an explicit test, we also found that both proximity to roads and traffic volume were associated with higher GUDs. We also found that maximum distance from roads was significantly higher for campuses and parks than for residential yards, indicating a greater proportion of the area of campuses and parks is "away from roads" compared to residential yards. Our results indicate that vehicle traffic may contribute significantly to an "urban landscape of fear" for gray squirrels and suggest that campus and park configurations that reduce road effects could improve habitat quality for squirrels and possibly other animals.

\section{Introduction}

Over half of the global human population currently lives in cities, and an additional 2.5 billion urban residents are predicted by 2050 (UN Desa 2018). This rapid increase in urbanization has significant impacts on ecosystems - urbanized areas produce more human-associated carbon emissions than any other source, and urbanization is considered the most irreversible form of human-driven land use change (Alberti et al. 2017; Elmqvist et al. 2019). As non-urban areas (including grasslands, forests, and other habitats) are increasingly transformed into agriculture fields or other developed landscape, more emphasis is being placed on how design and management can transform contemporary cities from ecological deficits to natural refugia for biodiversity with benefits for both non-human and human residents (Lewis et al. 2019; Fidino et al. 2021; Folke et al. 2021; Vega and Kueffer 2021).

One approach for increasing biodiversity in cities is through the protection and enhancement of green infrastructure, defined as "all natural, semi-natural and artificial networks of multifunctional ecological systems within, around and between urban areas" (Tzoulas et al. 2007). Numerous recent studies have explored how quantity, structure, connectedness, and other aspects of green infrastructure can provide ecosystem services (Ahern 2013; Lovell and Taylor 2013; Cheng et al. 2015; Pamukcu-Albers et al. 2021; Wang et al. 2021). Given the extensive densification occurring in many cities (Liu et al. 2020), there is increasing emphasis on increasing the ecological value of this infrastructure (Vega and Kueffer 2021).

One potentially important existing source of green infrastructure is higher education campuses. College campuses can cover a significant amount of space in urban areas. For example, in Minneapolis-St. Paul 
MN (the focal location of the current study, hereafter "the Twin Cities"), campuses of the 15 main higher education institutions cover 4810 acres, which is $41 \%$ of the combined area covered by parks in the Minneapolis and St. Paul Parks systems (11,871 acres; Table S1). This result is especially notable given that Minneapolis and St. Paul Parks systems are consistently rated as some of the best in the US in part because of their extent (www.tpl.org/parkscore). College campuses in urban areas often include green space ranging from manicured courtyards and tree-lined walkways to forest patches. Colleges often foreground these green spaces in efforts to recruit and retain students (Hajrasouliha and Ewing 2016). In addition, objective and perceived greenness on college campuses is associated with higher quality of life metrics (Gulwadi et al. 2019; Holt et al. 2019), an important precursor to learning and overall well-being (Yildirim et al. 2013). This connection between ecological conditions and educational goals, coupled with the significant space footprint of college campuses in urban areas, creates the potential for campuses to serve as important tools in developing urban areas as biological refugia. Additional research on the impact of the ecological features of college campuses could thus have broader conservation value.

In this study, we employ a widely used ecological technique, giving-up densities (GUDs), to help assess the quality of urban greenspace for wildlife. The GUD technique involves using feeding trays that create diminishing returns from foraging to estimate the density of resources in foraging patches at which a forager will cease foraging (or "give up"). If foragers behave optimally, resource gain to the forager at this GUD will equal marginal foraging costs, which are a function of energy and material demands of foraging, predation risk, and missed opportunity costs associated with foraging (Brown 1988). The GUD technique thus provides a relatively simple but powerful way to assess how foragers perceive habitat quality (Brown 1992). In the last few decades, this technique has been used in hundreds of studies on a wide range of animals (e.g., Kotler et al. 1991; Brown 1999; Kay 2002; Brown and Kotler 2004; Verdolin 2006; Shochat et al. 2010; Abu Baker et al. 2021).

We assess GUDs for the eastern gray squirrel, Sciurus carolinensis, in the Twin Cities, MN, USA. The eastern gray squirrel is one of most common wildlife species in Minnesota and is abundant in urban and suburban areas in the state (www.dnr.state.mn.us). Gray squirrels have acclimated to urban

environments in the US over the past $~ 150$ years and have rapidly extended their geographic range in part because of the development of urban park systems (Benson 2013). Peplinski and Brown (2020) found that gray squirrels are also common on college campuses, being reported on $62 \%$ of 536 campuses in Canada and the United States included in their survey. The Twin Cities is an ideal location for the study given the prevalence of urban parks and college campuses and the presence of the MSP Urban Long Term Ecological Research program.

In this two-part study, we first assess whether GUDs differ among three types of green infrastructure and then test explicitly how a key feature of green infrastructure, proximity to roads, influences GUDs. Roads have been a focus for decades of research on how human activities impact wildlife (Forman and Alexander 1998, Muñoz et al. 2015). Main negative impacts of roads include habitat fragmentation and direct mortality due to collision (Smith-Patten and Patten 2008, Jackson and Fahrig 2011). Much less is known about impacts of roads on risks perceived by foragers, particularly in urban environments. 
However, due to the prevalence of roads and vehicles in US cities, road effects may have significant impacts on urban habitat value for many animals.

\section{Methods}

\section{Study Site}

In part 1 of the study, we used seeds trays to assess squirrel GUDs in three locations: college campuses, municipal parks, and residential yards. For college campuses, we sought permission to sample from 9 colleges or universities located in St. Paul or Minneapolis and received positive responses from Grounds Department managers or other administrators at 6 of them: University of St. Thomas, Macalester College, Hamline University, Minneapolis College of Art and Design, St Catherine University, and Metropolitan State University. For parks, we obtained permission from the Minneapolis and St. Parks and Recreation Departments, and then selected 7 parks that were comparable in size to the college campuses used in the survey. All campuses and parks were surrounded by residential areas. For residential yards, we recruited households using a survey distributed through social media that asked whether they were willing to allow foraging trays to be placed in their yard during daylight hours. Forty-nine households responded, and 48 were included in the survey.

In part 2 of the study, we assessed the effect of road proximity on squirrel GUDs on one college campus in St. Paul (University of St. Thomas).

\section{Study Species}

Eastern gray squirrels are common in urban areas in Minnesota, both in parks and residential yards. They are diurnal foragers and eat a wide range of nuts, seeds, and human refuse. They have several predators, including domestic cats and dogs. Squirrels are considered "nuisance animals" in Minnesota by statute and can be removed without a license in most areas (https://www.dnr.state.mn.us/livingwith_wildlife/taking.html). They are also common in roadkill surveys (Smith-Patten and Patten 2008), suggesting roads pose a significant mortality threat for them.

\section{Gud Technique}

We used artificial food patches (hereafter $=$ tray) to assess GUDs. Each tray consisted of an aluminum pie pan ( $23 \mathrm{~cm}$ diameter, $2 \mathrm{~cm}$ depth) filled with $8.25 \mathrm{~g}$ sunflower seeds ( 200 seeds) mixed thoroughly into $\sim 0.5 \mathrm{~L}$ of playground sand. We deployed trays between $0630-0800$ and collected them between 1830 - 2000 on days without precipitation during July and August 2021. After collecting, we sifted trays, hand counted remaining seeds, and then back-transformed seed number to mass in grams. All experiments involved indirect feeding of free-ranging animals; no animal welfare issues arose. 


\section{Experimental Design}

In part 1, we tested whether GUDs differed among locations (parks, campuses, and residential yards) both near and away from roads. For each of 7 parks and 6 campuses, we placed 3 trays along each road that borders the site (as many as 12 road trays total per place) and 10 trays within the interior of the site (="away from road"). For the near-road tray, we placed one tray $2.5 \mathrm{~m}$ from the road at least $5 \mathrm{~m}$ from the nearest tree trunk. If there was a sidewalk $2.5 \mathrm{~m}$ from the road, we placed the tray $0.5 \mathrm{~m}$ from the interior edge of the sidewalk. For away-from-road trays, we divided all areas of the property without permanent structures (including parking lots) into 8 areas of equal size and then randomly assigned trays to areas. We deployed trays to each campus or park on two different days ( 6 road +5 away-from-road trays on each day) with deployments at the same site separated by at least 3 days. For each of 48 residential yards, we deployed two trays, one near the road and one in the interior of the yard, on different days. We deployed near-road trays in yards as described for parks and campuses, above. For the away-from-road residential tray, we divided yards (all areas of a property without permanent structures) into quadrats and randomly selected one quadrat for deployment. We then set the tray haphazardly within the selected quadrat, at least $5 \mathrm{~m}$ away from tree trunks and at least $2 \mathrm{~m}$ away from any permanent structure. We randomized the order of tray deployment (road vs away from road) separately for each home and waited at least 3 days between deployments at the same home. For all trays, we placed a small sign $\sim 0.5 \mathrm{~m}$ away to discourage human interference. For all three location types, we placed a limited number of motion-sensitive cameras $\sim 1 \mathrm{~m}$ from trays to identify visitors to the foraging trays.

We analyzed these data using a general linear mixed model (GLMM) with location type (yard, campus, or park) and proximity to road (yes/no) as independent variables and GUD as the dependent variable. Site (=yard address, campus identity, park identity) was included as random effect since multiple sampling events occurred at a given location.

To estimate "maximum distance from a road" at each location, we measured the point in a property (yard, campus, or park) that was furthest from any road using google maps and ImageJ software.

In part 2, we tested explicitly the impact of proximity to roads on GUDs. We deployed all trays for this component on the University of St. Thomas campus. We estimated traffic volume on each of the four roads bordering the southern part of the campus using 2 15-min samples per road (at 12:00-13:00 and at 16:00-18:00, periods of typically high traffic) in which we counted every vehicle passing in each direction. We then used these counts to classify roads as "high traffic" (one road) or "low traffic" (3 roads). For each of the 4 roads, we then placed 4 trays at each of 5 locations $(0.5 \mathrm{~m}, 2 \mathrm{~m}, 4 \mathrm{~m}, 8 \mathrm{~m}$, and $16 \mathrm{~m}$ from the edge of the road) with each tray at least $5 \mathrm{~m}$ away from tree trunks, at least $2 \mathrm{~m}$ away from any permanent structure, and at least $15 \mathrm{~m}$ away from other trays. We analyzed these data using GLMM with distance to road and road type as independent variables and GUD as the dependent variable. We performed all statistical analyses using JMP Pro 15.

\section{Results}


We found that GUDs differed within but not among location types (Fig. 1). Using all tray data, we found that mean GUD did not differ significantly among parks, campuses, and residential yards $\left(F_{2,15.54}=\right.$ $0.924, p=0.418$ ), but did differ significantly within location type depending upon proximity to roads $\left(F_{1}\right.$, $290.4=42.757, p<0.0001)$. There was no significant location-by-road proximity interaction $\left(F_{1,290.5}=\right.$ $2.178, p=0.115)$. Overall, $52 \%$ of seeds were removed from trays away from roads and only $26 \%$ of seeds were removed from trays near roads. A much higher percentage of trays away from roads were visited compared to trays near roads in all three location types (parks: away $72 \%$ vs near $56 \%$, campuses: $82 \%$ vs. $45 \%$, yards: $93 \%$ vs $64 \%$ ). When we restricted analysis only to trays that were visited (i.e., with remaining seed mass < initial seed mass), we still found that mean GUDs differed significantly depending on proximity to roads $\left(F_{1,189.4}=15.817, p<0.0001\right)$ but did not differ among location type $\left(F_{2,23.11}=\right.$ $0.211, p=0.812$ ). Camera traps captured pictures of 124 foragers, and $100 \%$ of pictured foragers were squirrels. Eighty-nine of these squirrels could be identified to species from the picture, and all 89 were eastern gray squirrels.

When we directly tested the association between road proximity and GUDs, we found that both greater distance to roads and higher traffic volume were associated with higher GUDs (Fig. 2). In our traffic survey, we found that traffic volume on one road was more than $7 \mathrm{x}$ higher than average traffic volume on the other 3 roads (mean \pm 1 SE: "high traffic" road $=13.4 \pm 1.4$ vehicles $/ \mathrm{min}$, "low traffic" roads $=1.95 \pm$ 0.63 vehicles/ $\mathrm{min}$ ). Overall, GUDs were significantly higher near the high traffic road than near the lower traffic roads $\left(F_{1,76}=6.002, p=0.017\right)$ and decreased significantly with distance from roads under both traffic conditions $\left(F_{1,76}=4.976, p=0.029\right)$. There was no significant traffic level-by-distance from road interaction $\left(F_{1,76}=0.029, p=0.865\right)$. GUDs at the furthest distance used in part 2 of the study $(16 \mathrm{~m})$ were significantly higher than GUDs from away-from-road trays measured in part 1 (high traffic road: $t=3.998$, $d f=8.975, p=0.003$; low traffic roads: $t=2.929, d f=18.176, p=0.009)$.

We also found that maximum distance from roads within each site differed significantly among location type and was shorter for residential yards than for parks or campuses (Table S2).

\section{Discussion}

Our results indicate that, compared to residential yards, both college campuses and parks may be associated with reduced foraging costs for eastern gray squirrels because of the amount of greenspace that is distant from roads. In part 1, we found that GUDs for gray squirrels did not differ significantly among parks, campuses, and yards after controlling for proximity to roads, but proximity to roads was associated with significantly higher GUDs in all location categories. In an explicit test, we also found that proximity to roads and traffic volume were both associated with higher GUDs. We found that maximum distance from roads was significantly higher for campuses and parks than for residential yards, indicating a greater proportion of the area of campuses and parks is "away from roads." Our results, although preliminary, suggest that campus and park configurations that reduce road effects should 
reduce foraging costs and increase habitat quality for gray squirrels. More generally, these results suggest that reducing vehicle traffic may be essential for creating urban refugia for some species.

Much evidence suggests that vehicle traffic generally negatively impacts wildlife, but the extent to which urban road use impacts animal foraging costs is not well documented. In general, roads are much more likely to have negative effects on animal abundances and behavior than positive effects (Speziale et al. 2008; Fahrig and Rytwinski 2009; Baxter-Gilbert et al. 2015), and limited evidence suggests that at least major roadways limit movement of eastern gray squirrels (Hennessy et al. 2018, although see Fey et al. 2018 for a contrasting result for urban red squirrels). Our results showing higher GUDs closer to urban roads suggest that road proximity and traffic affect gray squirrels' perception of risk. Furthermore, our results in part 2 suggest that this road effect may extend at least $16 \mathrm{~m}$ in from roads. These results suggest that squirrels may experience an urban "landscape of fear" that is similar to predation risk effects in non-human-dominated ecosystems. The landscape of fear concept has been advanced in ecology as a general mechanism linking individual behavior to community and ecosystem consequences (Brown and Kotler 2004; Schmitz 2005; Laundré et al. 2010; Gaynor et al. 2019). Further research should explore whether traffic variation creates similar peaks and valleys in risk for urban animals that in turn influence urban ecosystem processes. Research should also investigate whether the magnitude of road effects can be mediated by parked cars, bike lanes, or other barriers separating vehicles from greenspace.

Factors other than road proximity, including predation risk, shelter, and food availability also likely influence the value of green infrastructure for gray squirrels in urban areas. Across a rural-urban gradient, Bowers and Breland (1996) found that gray squirrels had lower GUDs (lower costs) near human structures and abundant trees, but higher GUDs where there was abundant ground cover and more domestic cats and dogs. Gray squirrels in urban areas are one of the most common prey items of domestic cats (Loyd et al. 2017) and other urban predators. In addition, squirrels have also long been known to modify foraging behavior in the face of predation risk (Lima and Valone 1986), and this response is mediated by shelter availability (Lima et al. 1985). Humans also likely increase perceived predation risk for squirrels, although habituation to human presence (Engelhardt and Weladji 2011) and predictability of human behavior (Bateman and Fleming 2014) can reduce squirrel perception of risk. Food availability is likely also an important factor influencing foraging costs for squirrels. This relationship is illustrated by a "habitat suitability index" for gray squirrels in urban cemeteries developed by McPherson and Nilon (1987) that primarily emphasized tree cover that contributed to the availability of winter food quality and quantity. More broadly, Fidino et al. (2021) found that gray squirrels are positively associated with housing density, and their overall response to urbanization changed from negative to positive once total greenspace area in cities increased to over $20 \%$ of total area. Future work could examine how specific environmental factors and total greenspace interact with traffic volume to determine foraging costs for gray squirrels, and whether habituation to traffic can reduce costs from perceived risk as it does to direct human exposure.

Interpretation of our GUD results must be made with some caution for two reasons. First, our results are to some extent correlational because we tested GUD associations with proximity to roads and traffic 
volume but did not manipulate traffic volume directly. Second, we cannot rule out the possibility that animals other than gray squirrels visited our foraging trays. Bedoya-Perez (2013) identified the potential for non-target visitors to feeding trays as the most important complication with interpreting GUD experiments and recommended researchers use behavioral observations to overcome this challenge. Here, we used camera traps to make such observations and found that all of our 124 pictures of foragers were squirrels and all 89 identifiable squirrels in pictures were gray squirrels. However, these pictures likely represent only a small fraction of the total visitation to trays in our study and it is possible that visitation by other foragers impacted results to some extent.

Our results suggest that reducing traffic volume and increasing the proportion of urban greenspace that is distant from roads will decrease foraging costs and increase habitat quality for gray squirrels, but more work is needed before we can draw conclusions about whether squirrel perception of habitat quality coincides with general habitat value for wildlife and human well-being. Fidino et al. (2021) used abundance data on gray squirrels and other mammals to identify urban design features that better support biodiversity and reduce negative influences of urbanization on wildlife. Environmental features that were associated with more gray squirrels were also associated with greater abundances of other mammals (fox squirrels, red foxes), suggesting gray squirrel habitat quality measures may be generally useful for identifying habitat quality for urban wildlife. However, gray squirrels are significant nest predators in their native range (Malpass et al. 2015) and are viewed as significant pests and targets for eradication in European cities in which they have been introduced (La Morgia et al. 2017; Broughton 2020), suggesting limits to the utility of using gray squirrel perceptions as a general metric of urban habitat value for wildlife. In terms of human well-being, it is beyond the scope of this paper to assess whether less vehicle traffic and more protected greenspace to benefit gray squirrels would also generally benefit humans. It is worth noting, however, that both McPherson and Nilon (1987) and Peplinski and Brown (2020) suggested that managing habitat for gray squirrels can contribute positively to human experiences in cemeteries and college campuses, respectively. Future work should explore whether college campuses in which squirrels have lower foraging costs are more conducive to learning and positive mental health. More generally, it might be worth considering whether managing whole cities for gray squirrels could generally improve quality of life for human residents.

\section{Statements And Declarations}

The authors have no financial or non-financial interests that are directly or indirectly related to the work submitted for publication.

Acknowledgments We are grateful to participating households, staff at participating campuses, and the Minneapolis and St. Paul Parks departments for providing access to study sites. This work was made possible [in part] by funding from the University of St. Thomas and by the Minneapolis-St. Paul Metropolitan Area (MSP) Urban Long Term Ecological Research Program, through its grant from the National Science Foundation (DEB-2045382). 
\# Funding: This work was made possible [in part] by funding from the University of St. Thomas and by the Minneapolis-St. Paul Metropolitan Area (MSP) Urban Long Term Ecological Research Program, through its grant from the National Science Foundation (DEB-2045382).

\# Conflicts of interest/Competing interests: The authors have no financial or non-financial interests that are directly or indirectly related to the work submitted for publication.

\# Availability of data and material: all data and materials support published claims and comply with field standards. Research data will be made available in concordance with the standards of Urban Ecosystems

\# Code availability: Not relevant

\# Authors' contributions: All authors helped design the work and draft the manuscript. All authors approve of the submitted version

\# Ethics approval: All experiments involved indirect feeding of free-ranging animals; no animal welfare issues arose.

\section{References}

1. Abu Baker MA, Emerson SE, Gorman J, Brown JS (2021) Dietary choices in a generalist herbivore, the eastern cottontail Sy/vilagus floridanus, in urban landscapes. Behaviour 158:377-395

2. Ahern J (2013) Urban landscape sustainability and resilience: the promise and challenges of integrating ecology with urban planning and design. Landsc Ecol 28:1203-1212

3. Alberti M, Correa C, Marzluff JM, Hendry AP, Palkovacs EP, Gotanda KM, Hunt VM, Apgar TM, Zhou Y (2017) Global urban signatures of phenotypic change in animal and plant populations. PNAS 114:8951-8956

4. Bateman PW, Fleming PA (2014) Does human pedestrian behaviour influence risk assessment in a successful mammal urban adapter? J Zool 294:93-98

5. Baxter-Gilbert JH, Riley JL, Neufeld CJH, Litzgus JD, Lesbarrères D (2015) Road mortality potentially responsible for billions of pollinating insect deaths annually. J Insect Conserv 19:1029-1035

6. Bedoya-Perez MA, Carthey AJR, Mella VSA, McArthur C, Banks PB (2013) A practical guide to avoid giving up on giving-up densities. Behav Ecol Sociobiol 67:1541-1553

7. Benson E (2013) The urbanization of the Eastern Gray Squirrel in the United States. J Amer Hist 100:691-710

8. Bowers MA, Breland B (1996) Foraging of gray squirrels on an urban-rural gradient: use of the GUD to assess anthropogenic impact. Ecol Appl 6:1135-1142

9. Broughton RK (2020) Current and future impacts of nest predation and nest-site competition by invasive eastern grey squirrels Sciurus carolinensis on European birds. Mamm Rev 50:38-51 
10. Brown JS (1988) Patch use as an indicator of habitat preference, predation risk, and competition. Behav Ecol Sociobiol 22:37-47

11. Brown JS (1992) Patch use under predation risk: I. Models and predictions. Ann Zool Fenn 29:301309

12. Brown JS (1999) Vigilance, patch use and habitat selection: foraging under predation risk. Evol Ecol Res 1:49-71

13. Brown JS, Kotler BP (2004) Hazardous duty pay and the foraging cost of predation. Ecol Lett 7:9991014

14. Cheng XY, Wei BS, Chen G, Song CH (2015) Influence of park size and its surrounding urban landscape patterns on the park cooling effect. J Urban Plan Dev 141 (3)

15. Elmqvist T, Andersson E, Frantzeskaki N, McPhearson T, Olsson P, Gaffney O, Takeuchi K, Folke C (2019) Sustainability and resilience for transformation in the urban century. Nat Sustain 2:267-273

16. Engelhardt S, Weladji R (2011) Effects of levels of human exposure on flight initiation distance and distance to refuge in foraging eastern gray squirrels (Sciurus carolinensis). Can J Zool 89:823-830

17. Fahrig L, Rytwinski T (2009) Effects of roads on animal abundance: an empirical review and synthesis. Ecol Soc 14:21

18. Fey K, Hamalainen S, Selonen V (2016) Roads are no barrier for dispersing red squirrels in an urban environment. Behav Ecol 27:741-747

19. Fidino M, Gallo T, Lehrer EW, Murray MH, Kay CAM, Sander HA, MacDougall B, Salsbury CM, Ryan TJ, Angstmann JL et al (2021) Landscape-scale differences among cities alter common species' responses to urbanization. Ecol Appl 31:article 02253

20. Folke C, Gren A, Larsson J, Costanza R (2021) Cities and the Biosphere. Ambio 50:1634-1635

21. Forman RTT, Alexander LE (1998) Roads and their major ecological effects. Ann Rev Ecol Syst 29:207-231

22. Gaynor KM, Brown JS, Middleton AD, Power M, Brashares JS (2019) Landscapes of fear: spatial patterns of risk perception and response. Trends Ecol Evol 34:355-368

23. Hajrasouliha AH, Ewing R (2016) Campus does matter: The relationship of student retention and degree attainment to campus design. Plan High Educ 44:30-45

24. Hennessy C, Tsai CC, Anderson SJ, Zollner PA, Rhodes OE (2018) What's stopping you? Variability of interstate highways as barriers for four species of terrestrial rodents. Ecosphere 9:e02333

25. Holt E, Lombard Q, Best N, Smiley-Smith S, Quinn J (2019) Active and passive use of green space, health, and well-being amongst university students. Int J Environ Res Public Health 16:424

26. Jackson ND, Fahrig L (2011) Relative effects of road mortality and decreased connectivity on population genetic diversity. Biol Conserv 144:3142-3148

27. Jessen T, Wang Y, Wilmers CC (2018) Habitat fragmentation provides a competitive advantage to an invasive tree squirrel, Sciurus carolinensis. Biol Invas 20:607-618 
28. Kay A (2002) Applying optimal foraging theory to assess nutrient availability ratios for ants. Ecology 83:1935-1944

29. Klein-Banai C, Theis TL (2011) An urban university's ecological footprint and the effect of climate change. Ecol Indic 11:857-860

30. Koprowski J, Munroe KE, Edelman A (2016) Gray not grey: ecology of Sciurus carolinensis in their native range in North America. In: Shuttleworth CM, Lurz PWW, Gurnell J (eds) The Grey Squirrel: Ecology and Management of an Invasive Species in Europe. European Squirrel Initiative, Bangor

31. Kotler BP, Brown JS, Hasson O (1991) Factors affecting gerbil foraging behavior and rates of owl predation. Ecology 72:2249-2260

32. La Morgia V, Paoloni D, Genovesi P (2017) Eradicating the grey squirrel Sciurus carolinensis from urban areas: an innovative decision-making approach based on lessons learnt in Italy. Pest Manag Sci 73:354-363

33. Laundré JW, Hernández L, Ripple WJ (2010) The landscape of fear: ecological implications of being afraid. Open J Ecol 3:1-7

34. Lewis AD, Bouman MJ, Winter AM, Hasle EA, Stotz DF, Johnston MK, Klinger KR, Rosenthal A, Czarnecki CA (2019) Does nature need cities? Pollinators reveal a role for cities in wildlife conservation. Front Ecol Evol 7

35. Lima SL, Valone TJ (1986) Influence of predation risk on diet selection: a simple example in the grey squirrel. An Behav 34:536-544

36. Lima SL, Valone TJ, Caraco T (1985) Foraging-efficiency-predation-risk trade-off in the grey squirrel. An Behav 33:155-165

37. Liu X, Huang Y, Xu X, Li X, Li X, Ciais P, Lin P, Gong K, Ziegler AD, Chen A, Gong P, Chen J, Hu G, Chen Y, Wang S, Wu Q, Huang K, Estes L, Zeng Z (2020) High-spatiotemporal-resolution mapping of global urban change from 1985 to 2015 . Nat Sustain 3:564-570

38. Lovell ST, Taylor JR (2013) Supplying urban ecosystem services through multifunctional green infrastructure in the United States. Landsc Ecol 28:1447-1463

39. Lowe S, Browne M, Boudjelas S, De Poorter M (2004) Hundred of the World's Worst Invasive Alien Species: A Selection from the Global Invasive Species Database. Invasive Species Specialist Group of the IUCN-World Conservation Union. The Invasive Species Specialist Group

40. Loyd KAT, Hernandez SM, McRuer DL (2017) The role of domestic cats in the admission of injured wildlife at rehabilitation and rescue centers. Wildl Soc Bull 41:55-61

41. Malpass JS, Rodewald AD, Matthews SN (2015) Woody cover does not promote activity of nest predators in residential yards. Landsc Urban Plan 135:32-39

42. McPherson EG, Nilon C (1987) A Habitat Suitability Index model for gray squirrel in an urban cemetery. Landsc J 6:21-30

43. Muñoz PT, Torres FP, Megías AG (2015) Effects of roads on insects: a review. Biodivers Conserv 24:659-682 
44. Pamukcu-Albers P, Ugolini F, La Rosa D, Grădinaru SR, Azevedo JC, Wu JG (2021) Building green infrastructure to enhance urban resilience to climate change and pandemics. Landsc Ecol 36:665673

45. Peplinski J, Brown JS (2020) Distribution and diversity of squirrels on university and college campuses of the United States and Canada. J Mammal 101:930-940

46. Preisser EL, Bolnick DI, Benard MF (2005) Scared to death? The effects of intimidation and consumption in predator-prey interactions. Ecology 86:501-509

47. Shochat E, Lerman SB, Anderies JM, Warren PS, Faeth SH, Nilon CH (2010) Invasion, competition, and biodiversity loss in urban ecosystems. Bioscience 60:199-208

48. Smith-Patten BD, Patten MA (2008) Diversity, seasonality, and context of mammalian roadkills in the southern great plains. Environ Manage 41:844-852

49. Speziale KL, Lambertucci SA, Olsson O (2008) Disturbance from roads negatively affects Andean condor habitat use. Biol Conserv 141:1765-1772

50. Tzoulas K, Korpela K, Venn S, Ylipelkonen V, Kaźmierczak A, Niemela J, James P (2007) Promoting ecosystem and human health in urban areas using green infrastructure: a literature review. Landsc Urban Plan 81:167-178

51. UN DESA (2018) World Urbanization Prospects: 2018. Available online at: https://population.un.org/wup/Publications/Files/WUP2018-KeyFacts.pdf

52. Vega KA, Kueffer C (2021) Promoting wildflower biodiversity in dense and green cities: The important role of small vegetation patches. Urban For Urban Green 62:127165

53. Verdolin J (2006) Meta-analysis of foraging and predation risk trade-offs in terrestrial systems. Behav Ecol Sociobiol 60:457-464

54. Wang YN, Chang Q, Li XY (2021) Promoting sustainable carbon sequestration of plants in urban greenspace by planting design: A case study in parks of Beijing. Urban For Urban Green 64:127291

55. Yildirim Y, Kilic S, Akyol A (2013) Relationship between life satisfaction and quality of life in Turkish nursing school students. Nurs Health Sci 15:415-422

\section{Figures}




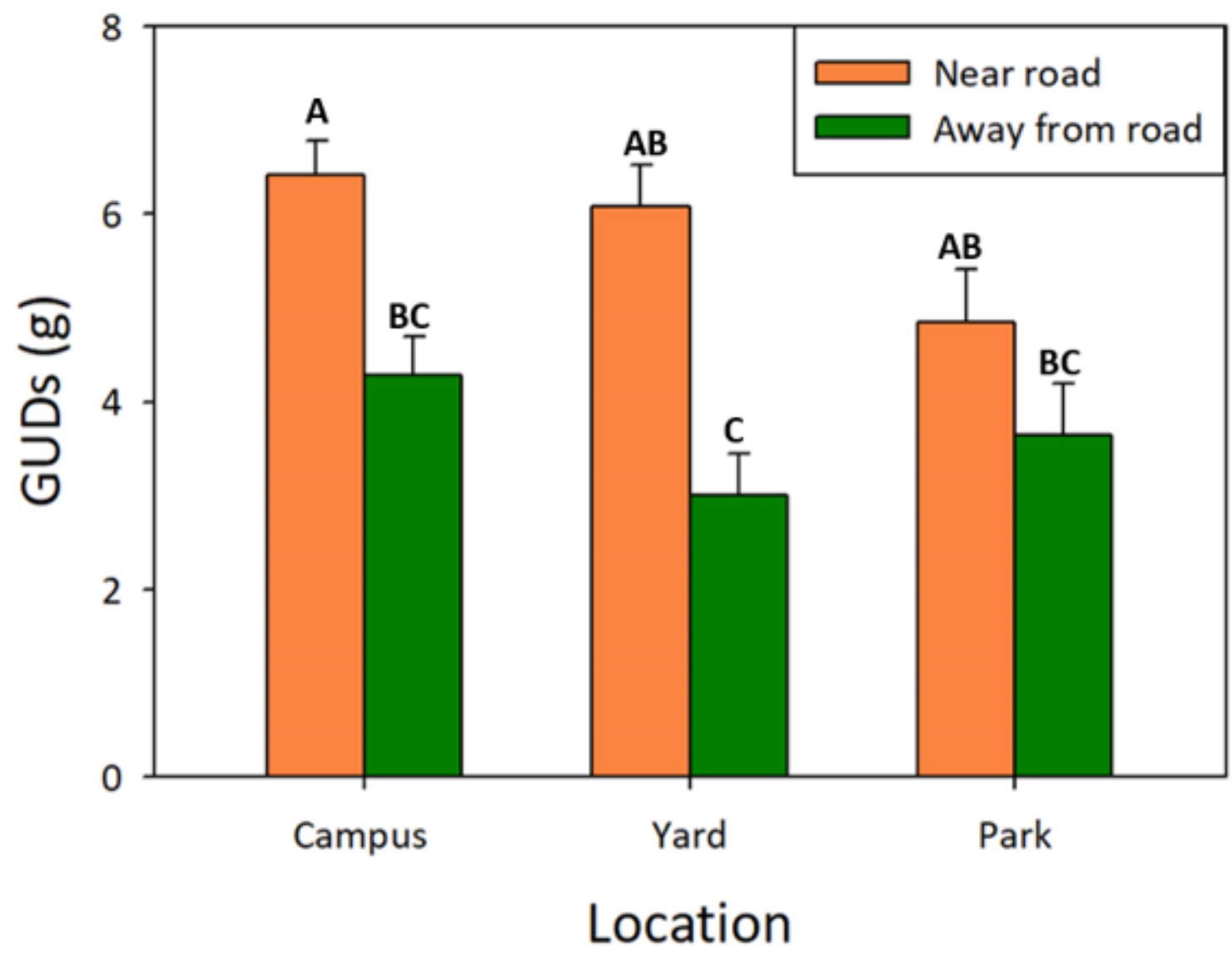

Figure 1

Relationship between giving-up density (GUD) (mean \pm 1 S.E.) and location type (higher education campus, residential yard, municipal park). 


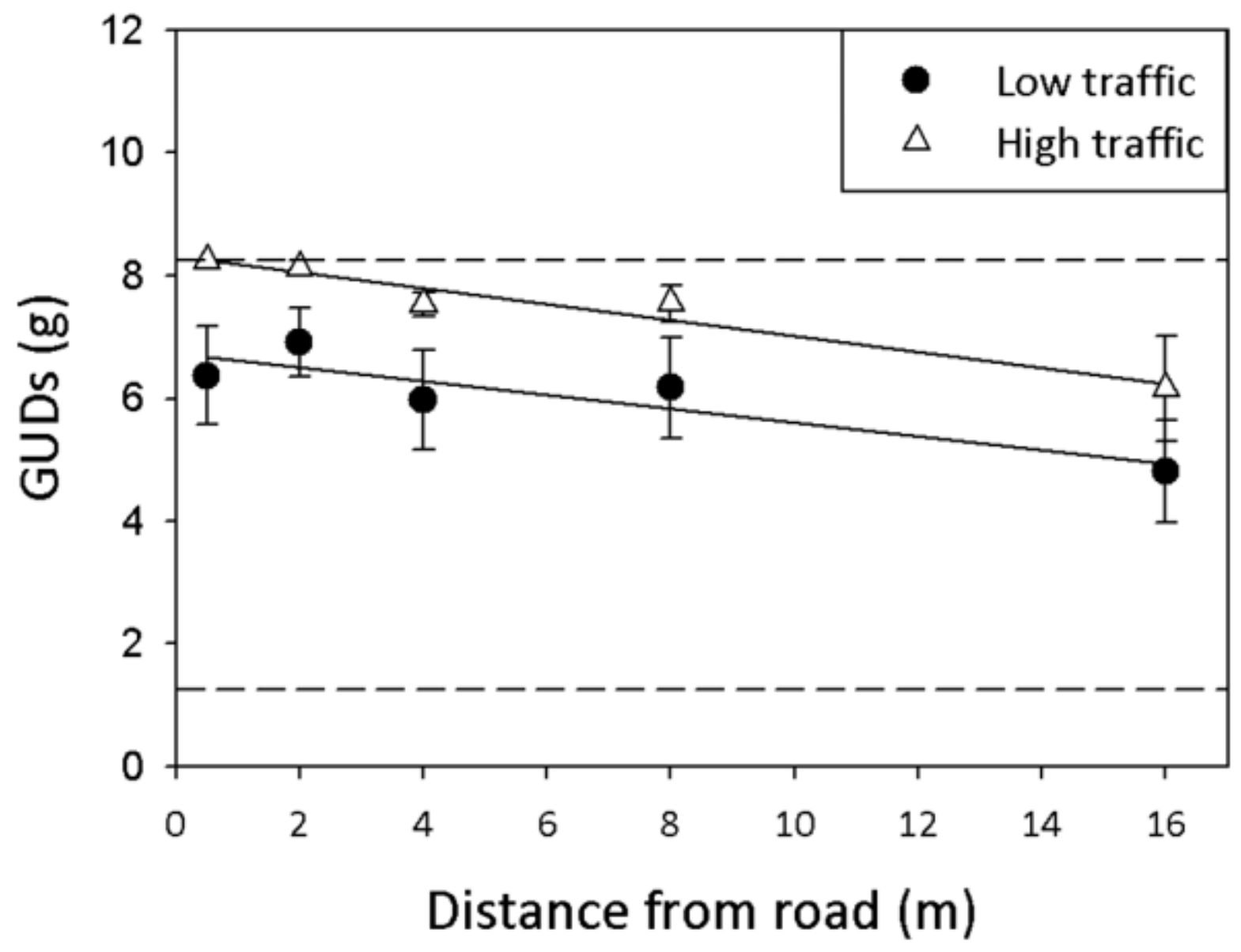

Figure 2

Relationship between giving-up density (GUD) (mean \pm 1 S.E.) and distance (in meters) from a high-traffic road and low-traffic roads. GUD data were collected at the University of St. Thomas (UST) over 2 days. Roads were categorized as high- or low-traffic as described in the text. Upper dashed line indicates original seed mass in trays (= "max GUD"). Lower dashed line indicates mean GUD for samples from samples taken away from roads on the UST campus.

\section{Supplementary Files}

This is a list of supplementary files associated with this preprint. Click to download.

- Supplementarytables.docx 